\title{
BMJ Open Progress and setbacks in socioeconomic inequalities in adolescent health-related behaviours in Brazil: results from three cross-sectional surveys 2009-2015
}

To cite: Azeredo CM, de Rezende LFM, Mallinson PAC, et al. Progress and setbacks in socioeconomic inequalities in adolescent health-related behaviours in Brazil: results from three cross-sectional surveys 2009-2015. BMJ Open 2019;9:e025338. doi:10.1136/ bmjopen-2018-025338

- Prepublication history and additional material for this paper are available online. To view these files, please visit the journal online (http://dx.doi. org/10.1136/bmjopen-2018025338).

Received 19 July 2018 Revised 5 January 2019 Accepted 28 January 2019

Check for updates

(c) Author(s) (or their employer(s)) 2019. Re-use permitted under CC BY-NC. No commercial re-use. See rights and permissions. Published by BMJ.

For numbered affiliations see end of article.

Correspondence to Professor Catarina

Machado Azeredo; catarina.azeredo@ufu.br

\section{ABSTRACT}

Objectives Despite some progress, Brazil is still one of the most unequal countries, and the extent of socioeconomic inequalities in adolescent health is unclear. We assessed trends in socioeconomic inequalities in adolescent's health-related behaviours in Brazil between 2009 and 2015

Design We used cross-sectional data from the Brazilian National Survey of School Health carried out in 2009, 2012 and 2015.

Setting Brazilian state capitals.

Participants Students attending ninth grade from public and private schools in Brazilian state capitals in 2009 (60 973 students), 2012 (61 145 students) and 2015 (51 192 students).

Main outcome measure We assessed 12 healthrelated behaviours (irregular fruit, vegetables and bean consumption; regular soft drink consumption; irregular physical activity; alcohol, drug and tobacco use; unsafe sex; involvement in gun fights; bullying victimisation and domestic violence victimisation), under the broad domains of lifestyle risk behaviours, engagement in risky activities and exposure to violence. Socioeconomic status was assessed through an asset-based wealth index derived from principal component analysis. Absolute and relative inequalities in these health behaviours and inequalities trends were investigated.

Results From 2009 to 2015, prevalence of certain harmful health-related behaviours increased, such as unsafe sex ( $21.5 \%$ to $33.9 \%)$, domestic violence $(9.5 \%$ to $16.2 \%)$, bullying victimisation (14.2\% to $21.7 \%$ ) and irregular consumption of beans ( $37.5 \%$ to $43.7 \%)$. Other indicators decreased: alcohol use $(27.1 \%$ to $23.2 \%)$, irregular physical activity (83.0\% to $75.6 \%$ ) and consumption of soft drinks (37.2\% to $28.8 \%$ ). Over the period, we found consistent evidence of decreasing health inequalities for lifestyle behaviours (fruit, bean and soft drink consumption) and alcohol use, set against increasing inequalities in violence (domestic violence, fights using guns and bullying victimisation).

Conclusion Socioeconomic inequality increased in the violence domain and decreased for lifestyle behaviours among Brazilian adolescents. Widening gaps in violence domain urge immediately policy measures in Brazil.
Strengths and limitations of this study

- We assessed the extent of socioeconomic inequalities in adolescent health and how it has changed over time in a middle-income country.

- We used large representative urban samples from Brazilian adolescents attending public and private schools.

Another strength of this study was the use of complex measures of inequality.

- Although we have used validated questionnaires, the self-report of behaviours may cause some degree of classification bias.

- The period of 6 years may be too short to expect significant changes in inequalities.

\section{INTRODUCTION}

Adolescence is a critical period for promotion of human development. During adolescence, biological, cognitive, emotional and social capabilities are founded and future patterns of adult health are established. ${ }^{1}$ Despite its clear importance, adolescent's health has been generally overlooked in social policies. In order to guide surveillance, investments and policy actions, a broad concept of adolescent health has been proposed by The Lancet Commission on adolescent health. This concept includes aspects related to sexual and reproductive health, nutritional deficiencies, injury and violence, physical and mental health and substance use disorders. ${ }^{2}$

Socioeconomic factors strongly predict adolescent health. ${ }^{3}$ Socioeconomic inequalities have consistently increased over the last decades in the USA and Europe, ${ }^{4}$ and this trend coincides with widening gaps in indicators of adolescent health. ${ }^{5}$ For instance, a time-series analysis of 34 North American and European countries showed an increase in inequalities between socioeconomic groups 
in physical activity, body mass index and psychological and physical symptoms between 2002 and $2010 .^{5}$

Studies monitoring inequality in adolescent health in low/middle-income countries are sparse in the literature. Brazil is still one of the most unequal countries worldwide, ${ }^{6}$ although considerable social protection efforts have been adopted in the last decades (eg, creation of a free public universal health system, expanding community-based primary care and providing a robust conditional cash transfer programme). ${ }^{7}$ These social programmes have had positive impacts on adult health, especially among the most deprived, with increased overall food quality and diversity, ${ }^{8}$ reduced racial inequalities in health ${ }^{9}$ and cardiovascular disease mortality. ${ }^{10}$ However, the extent of socioeconomic inequalities in adolescent health and how it has changed over time in Brazil is unclear.

In this study, we assessed levels and trends in socioeconomic inequalities in adolescent health in Brazil between 2009 and 2015, addressing absolute and relative measures of inequality. We used data from three large representative health surveys of adolescents living in Brazilian state capitals. We selected 12 indicators under three broad domains (lifestyle risk behaviours, engagement in risky activities and exposure to violence) to provide a holistic view of adolescent health inequalities in Brazil.

\section{METHODS}

We used cross-sectional data from three Brazilian National Surveys of School Health (Pesquisa Nacional da Saude do Escolar [PeNSE]) carried out in 2009, 2012 and 2015. In order to have comparable data sets across the three surveys, we used a representative subsample of adolescents attending ninth grade (ie, mostly aged between 14 and 15 years) in public and private schools from the 26 state capitals and the Federal District. Detailed information about PeNSE has been published elsewhere. ${ }^{11-13}$ Briefly, PeNSE sampling strategy included stratification per cluster and multistage selection. The sampling strata were each of the 26 state capitals and Federal District. The primary sampling units were schools, and the secondary sampling units were classrooms. School selection was proportional to the total number of ninth grade classes, while the classes in each school were chosen by simple random selection. Two classrooms were selected from schools with three or more ninth grade classrooms, whereas one classroom was selected from schools with one or two ninth grade classrooms. All students enrolled in the selected classrooms were invited to participate in the study. Participants were not included in the study if they did not attend school during data collection, refuse to participate or did not report their age and sex. The total number of students included in our analysis was 60973 (final response rate 83.8\%) for 2009, 61145 (final response rate $82.2 \%$ ) for 2012 and 51192 (final response rate $85.2 \%$ ) for 2015 surveys. ${ }^{11-13}$

Students filled out a self-reported structured questionnaire available in a personal digital Assistant device (2009 survey) or smartphone application (2012 and 2015 survey) in their school classrooms during regular school hours. The questionnaire was based on the Global School-Based Student Health Survey ${ }^{14}$ and the Youth Risk Behaviour Surveillance System, ${ }^{15}$ and was adapted to the Brazilian setting. Questions included socioeconomic variables and several risk and protective factors for adolescent health.

We estimated a wealth index specific for each survey year through principal component analysis (PCA), following the steps proposed by Barros and Victora. ${ }^{16}$ We ran PCA including the following variables: mother's educational level (incomplete middle school, complete middle school, complete high school, complete higher education); school administrative status (public or private); self-report of having: landline, mobile phone, computer, internet access, car, bathroom inside the house and housemaid services. We retained the first component of the analysis and calculated coefficients from the expression: coefficient=loading/SDx100. The individual scores were estimated from the $\sum c_{i} v_{i}$, where $c_{i}$ is the coefficient and $v_{i}$ is the value for the ith variable. The wealth index was assessed as quintiles of the total wealth scores. We refer to the first quintile $(\mathrm{Q} 1)$ as the poorest quintile (poorest 20\%) and the fifth quintile (Q5) as the wealthiest quintile (wealthiest 20\%).

The indicators of adolescent health used in this study are defined in table 1 . We divided indicators in three domains: lifestyle risk behaviours, engagement in risky activities and exposure to violence. Alcohol and tobacco use were included as risky activities and not lifestyle behaviours, because Brazilian law forbids the sale of these substances for younger than 18 years old. We have used the concept of 'irregular consumption' $(<5$ times in the past week) for all food indicators, following the complementary concept of 'regular consumption', which was validated using 24-hour recall. ${ }^{17}$ We also chose to include bean consumption because of their protective health effects and importance in Brazil as an affordable traditional staple food. ${ }^{18}$ The frequency of two or more times in the previous month for bullying victimisation followed the concept of this type of violence, which presume repetition. ${ }^{19}$ The unsafe sex was assessed only for those who reported had sexual relationships.

To assess socioeconomic inequalities in adolescent health, we used several measures of inequality. First, we estimated simple measures of inequality (pairwise comparisons), such as differences and ratios of each health indicator between the wealthiest group (fifth quintile) and the poorest group (first quintile).

Second, we estimated complex measures of inequality, represented by an indicator of absolute inequality, the slope index of inequality (SII), and an indicator of relative inequality, the concentration index (CIX). ${ }^{20}$ Both SII and CIX take into account all quintiles of the wealth index to compare a given health indicator across all wealth subgroups.

We estimated the SII using logistic regression to avoid predicting implausible values below 0 or above 1 , 
Table 1 Indicators of adolescent health used in the present study

\begin{tabular}{ll}
\hline Domain & Health indicator \\
\hline Lifestyle risk behaviours & $\begin{array}{l}\text { Regular dietary consumption of fruits } \\
(\geq 5 \text { days) in the last week }\end{array}$ \\
& \\
& $\begin{array}{l}\text { Regular dietary consumption of vegetables } \\
\text { ( } \geq 5 \text { days) in the last week }\end{array}$
\end{tabular}

\section{Original question}

In the 7 days, on how many days did you eat fresh fruits or fruits salad?

Options: I did not eat fresh fruits or fruits salad in the last

7 days; other options ranged from 1 day in the last 7 days to every day in the last 7 days.

In the 7 days, on how many days did you eat at least one type of raw or cooked vegetable?

Options: I did not eat vegetables in the last 7 days; other options ranged from 1 day in the last 7 days to every day in the last 7 days.

Regular dietary consumption of beans ( $\geq 5$ days) in the last week

In the 7 days, on how many days did you eat beans? Options: I did not eat beans in the last 7 days; other options ranged from 1 day in the last 7 days to every day in the last 7 days.

Regular dietary consumption of soft drinks ( $\geq 5$ days) in the last week

In the 7 days, on how many days did you drink soft drinks? Options: I did not drink soft drinks in the last 7 days; other options ranged from 1 day in the last 7 days to every day in the last 7 days.

Recreational physical activity at least five times in the last week

In the last 7 days, excluding physical education classes, on how many days did you practice any physical activity such as sports, dance, gymnastics, etc?

Options: No day in the last 7 days; other options ranged from 1 day in the last 7 days to every day in the last 7 days.

Exposure to violence Victim of domestic violence at least once in the previous month by some adult family member

In the last 30 days, how many times were you physically assaulted by some adult family member?

Options: Not once in the last 30 days; one time in the last 30 days; other options ranged from two to three times in the last 30 days to 12 or more times in the last 30 days.

Involvement in fights using guns at least one in the last month

In the last 30 days, did you get involved in any fight that someone used guns?

Options: yes; no

Bullying victimisation at least sometimes in the last month

In the past 30 days, how often have you been mocked, teased, called names or intimidated by one of your schoolmates so much that you were hurt/annoyed/upset/ offended/ashamed?

Options: No day in the last 30 days; rarely in the last 30 days; sometimes in the last 30 days; most of the time in the last 30 days; always in the last 30 days

Engagement in risky activities
Alcohol use at least once in the previous month

Drug use at least once in the previous month

Smoking at least once in the previous month

Safe sexual behaviour (have used condom in the last sexual intercourse)
In the last 30 days, on how many days did you drink at least one cup or dose of alcoholic beverage?

Options: No day in the last 30 days; Other options ranged from 1 to 2 days in the last 30 days to every day in the last 30 days.

In the last 30 days, how many times did you use drugs such as marijuana, cocaine, crack, glue, ecstasy, oxy, etc? Options: I have never used drugs; no day in the last 30 days Other options ranged from 1 or 2 days in the last 30 days to 10 or more days in the last 30 days.

In the last 30 days, on how many days did you smoke cigarettes?

Options: I have never smoked; No day in the last 30 days; Other options ranged from 1 to 2 days in the last 30 days to every day in the last 30 days.

In the last time you had sex, did you and your partner use a condom?

Options: I have never had sex; yes; no; I don't know. 
considering that all health indicators were presented as proportions. ${ }^{21}$ The SII estimates the absolute difference (ie, in percentage points) in the prevalence of health indicator between individuals in the wealthiest and poorest quintiles. Negative values of SII indicate that prevalence of the health indicator is higher among the poorest adolescents than the wealthiest (values ranged from -100 to +100$)$.

The CIX was also expressed on a scale ranging from -100 to +100 ; a value of 0 represents perfect equality, whereas negative values indicate that poor individuals have higher prevalence of a given health indicator than wealthy individuals. ${ }^{22}$ The CIX was calculated with no corrections. ${ }^{21}$

Linear regressions using variance-weighted least squares were performed to assess changes over time in complex measures of inequality (SII and CIX) based on the means and SD for each of the three surveys.

Multiple imputation was performed using the chained equation technique due to the significant proportion of missing values for the mother's education level in the three data sets $(19.36 \%, \mathrm{n}=33559)$. We also imputed other study variables with a smaller proportion of missing values, to create a complete data set. The imputed data exhibited satisfactory statistical reproducibility according to Monte Carlo error analysis. ${ }^{23}$

The sample design was taken into consideration for descriptive analyses, using survey prefix command (svy) in Stata. School clustering (random effect) and sample weights were considered when estimating complex measures of inequality (SII and CIX). All the statistical analyses were performed using Stata V.14.0.

\section{Ethics approval}

PeNSE surveys were approved by the National Commission of Research Ethics (Comissão Nacional de Ética em Pesquisa - Conep), records no. 11.537 (2009), 16.805 (2012) and 1.006.467 (2015). The surveys were performed in accordance with the Declaration of Helsinki and all participants gave their informed consent. Databases were made publicly available on an IBGE website without any information that could identify subjects.

\section{Patient and public involvement}

No patients or public were involved in the design and conceptualisation of this study.

\section{Data sharing}

The data set of 2009, 2012 and 2015 PeNSE are publicly available at: https://www.ibge.gov.br/estatisticas-novoportal/sociais/educacao/9134-pesquisa-nacional-desaude-do-escolar.html?=\&t=microdados

\section{RESULTS}

In 2015, the health-related behaviours more common among Brazilian adolescents were irregular consumption of fruits $(67.2 \%)$ and vegetables $(61.8 \%)$ and irregular recreational physical activity $(75.6 \%)$. Less frequent were the unsafe sex in last sexual intercourse $(33.9 \%)$, alcohol use $(23.2 \%)$ and exposure to bullying (21.7\%). Between 2009 and 2015, the prevalence of irregular vegetable consumption, irregular recreational physical activity, regular soft drink consumption and alcohol, tobacco and drug use decreased. On the other hand, trends for irregular bean consumption, unsafe sexual intercourse and exposure to violence (domestic violence, fight using guns and bullying victimisation) increased (table 2).

Figure 1A-C shows the trends in health indicators by wealth quintile between 2009 and 2015. The width of the bars represents the absolute inequality. For most health indicators (except bean, soft drink and alcohol use), people in the poorest group reported more adverse levels compared with the wealthiest group. In general, over the period 2009-2015, health inequalities decreased for lifestyle behaviours (fruit, vegetable, bean and soft drink consumption and recreational physical activity), while increased for risky activities and violence (smoking, drug use, unsafe sex, domestic violence, fights using guns and bullying victimisation) (see online supplementary appendix 1).

Some of these trends were not statistically significant according to complex measures of inequality (table 3 ).

In all years, alcohol consumption was the health indicator more equally distributed between wealth quintiles both according to absolute and relative measures. On the other hand, irregular vegetable consumption and unsafe sex had the highest absolute inequality and fights using guns and tobacco use the highest relative inequality. Over time, the absolute (SII) and relative inequalities (CIX) between wealth index quintiles became wider for all three indicators of exposure to violence, and narrower for some indicators of lifestyle behaviour (fruit, beans and soft drinks) and alcohol consumption. There was limited evidence of change in inequalities over time for the other lifestyle behaviours, such as irregular vegetable consumption and recreational physical activity, and indicators of engagement in risky activities, such as tobacco, drug use and unsafe sex (table 3 , figure 2 ).

\section{DISCUSSION}

We showed evidence of persistent socioeconomic inequalities in adolescent health in Brazil. Between 2009 and 2015, lifestyle behaviours (fruit and soft drink consumption) and alcohol use became more equally distributed between socioeconomic groups, while inequalities in experiencing violence were exacerbated. In this period, there was little evidence of change to inequalities in risky activities (smoking, drugs, unsafe sex).

In general, the direction of health inequalities we observed is similar to that reported in other settings, that is, poorer adolescents are more likely to report harmful health behaviours than richer. $^{5}$ For certain harmful behaviours (eg, alcohol and drug use), however, differences between social groups were not significant or 
Table 2 Brazilian adolescent characteristics and health-related behaviours from Pesquisa Nacional da Saude do Escolar surveys 2009, 2012 and 2015

\begin{tabular}{|c|c|c|c|c|c|c|}
\hline \multirow{3}{*}{$\begin{array}{l}\text { Adolescents characteristics and } \\
\text { behaviours } \\
\text { Characteristics }\end{array}$} & \multicolumn{6}{|c|}{ PeNSE survey year } \\
\hline & \multicolumn{2}{|c|}{2009 (60 973 students) } & \multicolumn{2}{|c|}{2012 (61 145 students) } & \multicolumn{2}{|c|}{2015 (51 192 students) } \\
\hline & $\%$ & $95 \% \mathrm{Cl}$ & $\%$ & $95 \% \mathrm{Cl}$ & $\%$ & $95 \% \mathrm{Cl}$ \\
\hline Age (mean and SE) & 14.2 & $(0.02)$ & 14.3 & $(0.02)$ & 14.2 & $(0.02)$ \\
\hline Wealth index (mean and SE) & 3.8 & $(0.03)$ & 4.0 & $(0.06)$ & 4.0 & $(0.06)$ \\
\hline Irregular vegetable consumption & 68.8 & (68.0 to 69.5$)$ & 64.1 & (63.3 to 64.9$)$ & 61.7 & (60.7 to 62.7$)$ \\
\hline Irregular bean consumption & 37.4 & (36.4 to 38.5$)$ & 40.0 & (38.5 to 41.5 ) & 43.7 & (42.4 to 45.1$)$ \\
\hline Regular soft drink consumption & 37.2 & (36.3 to 38.2$)$ & 35.4 & (34.6 to 36.2$)$ & 28.8 & (27.9 to 29.8$)$ \\
\hline Irregular recreational physical activity & 83.0 & (82.3 to 83.6$)$ & 74.2 & (7.5 to 74.8$)$ & 75.6 & (74.8 to 76.3 ) \\
\hline Unsafe sex (in the last sexual intercourse) & 21.5 & (20.3 to 22.7 ) & 22.5 & (21.6 to 23.5$)$ & 33.9 & (32.3 to 35.4 ) \\
\hline Domestic violence (once in the last month) & 9.5 & (9.1 to 10.0$)$ & 11.6 & (11.1 to 12.1$)$ & 16.2 & (15.5 to 16.9$)$ \\
\hline $\begin{array}{l}\text { Involvement in gun fights (once in the last } \\
\text { month) }\end{array}$ & 4.0 & (3.7 to 4.3 ) & 6.9 & (6.6 to 7.3$)$ & 5.6 & (5.2 to 6.1$)$ \\
\hline $\begin{array}{l}\text { Bullying victimisation (twice or more in the } \\
\text { last month) }\end{array}$ & 14.2 & (13.6 to 14.7$)$ & 16.5 & (15.9 to 17.1$)$ & 21.7 & (21.1 to 22.4$)$ \\
\hline
\end{tabular}

went in the opposite direction (ie, wealthier adolescents reported higher prevalences). These findings are consistent with results observed in other countries. ${ }^{24}$

Looking at time trends in these inequalities, our findings differ to existing evidence from Western Europe and North America. For some lifestyle (eg, vegetable consumption, physical activity) and risky behaviours (drug and tobacco use), inequalities have not changed significantly between 2009 and 2015 in Brazil. Yet inequality in lifestyle and risky behaviours have increased over similar period in many other countries. ${ }^{525}$ Similarly to ours, one study found persistent inequality in vegetable consumption. ${ }^{26}$ Despite this, comparable data for many indicators of risk behaviours are lacking. Rates of violence as well as inequalities in violence increased markedly (gun fights, domestic violence, bullying), and these trends also differ from other countries. ${ }^{27}$

Reasons for differential socioeconomic inequality trends between lifestyle behaviours, risk behaviours and violence-related indicators in Brazilian adolescents are unclear. Reductions in lifestyle behaviour inequalities fit with the general trend of narrowing economic and health inequalities observed for adults in Brazil in that period. ${ }^{28}{ }^{29}$ This is often attributed to rising prosperity combined with roll out of redistributive health and social programmes such as the Bolsa Familia cash transfer programme,$^{30}$ as well as scaled-up health promotion efforts (especially obesity prevention). ${ }^{31}$ Exacerbation of violence-related inequalities has also been observed in one study of adult mortality in Salvador. ${ }^{32}$ It has been suggested that public health interventions have focused on reducing infectious and chronic diseases but neglect, on the other hand, external causes of ill health such as interpersonal violence. In fact, violence-related mortality has declined slower than all other causes in Brazil, and even increased in 19 of the 27 states. $^{33}$

It is worth noting that we found a shift in prevalence of alcohol use and soft drink consumption between socioeconomics in the period studied. In 2009, these indicators were higher among the wealthiest group, but in 2015 , the differences were considerably attenuated. The reduction in the consumption of these products was more pronounced among the wealthiest group than in the poorest group. Conversely, for bean consumption, poorer adolescents reported higher prevalence than wealthiest adolescences. In this regard, the reduction in disparities between wealth groups should be read with caution. In high-income countries, poorer individuals consume more alcohol, relative to wealthier individuals, while in low/middle-income countries wealthier individuals are more exposed than the poorer. ${ }^{34}$ This trend could be shifting. In fact, industries of unhealthy commodities have moved to, and are growing faster in, low/middle-income countries compared with high-income countries. ${ }^{35}$ This phenomenon might explain, at least in part, the increase in consumption of ultraprocessed products (eg, sugary drinks) and alcohol, and the reduction of bean consumption in these settings. ${ }^{36}$ Brazil seems to be moving towards patterns of health indicators and their inequalities currently observed in high-income countries. 
A. Lifestyle risk behaviours

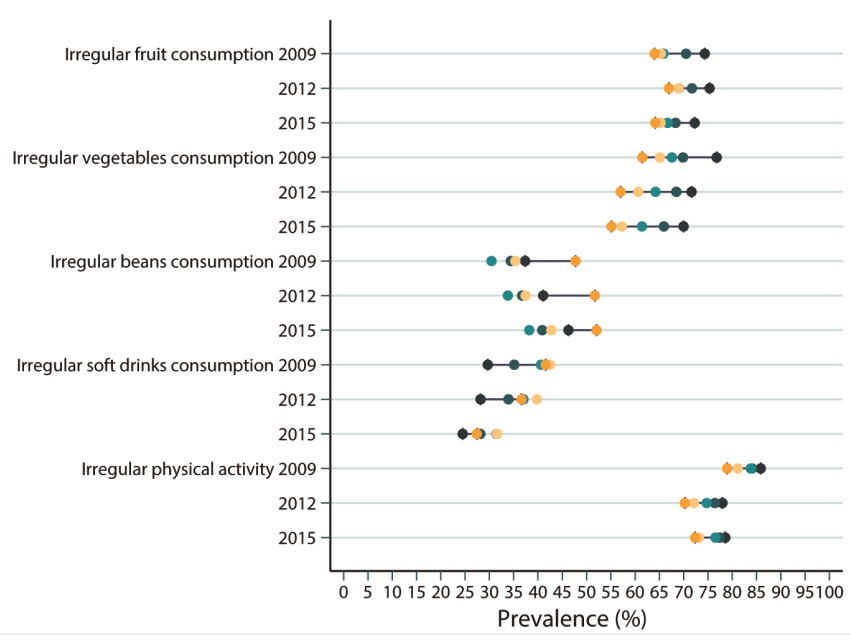

\section{Exposure to violence}

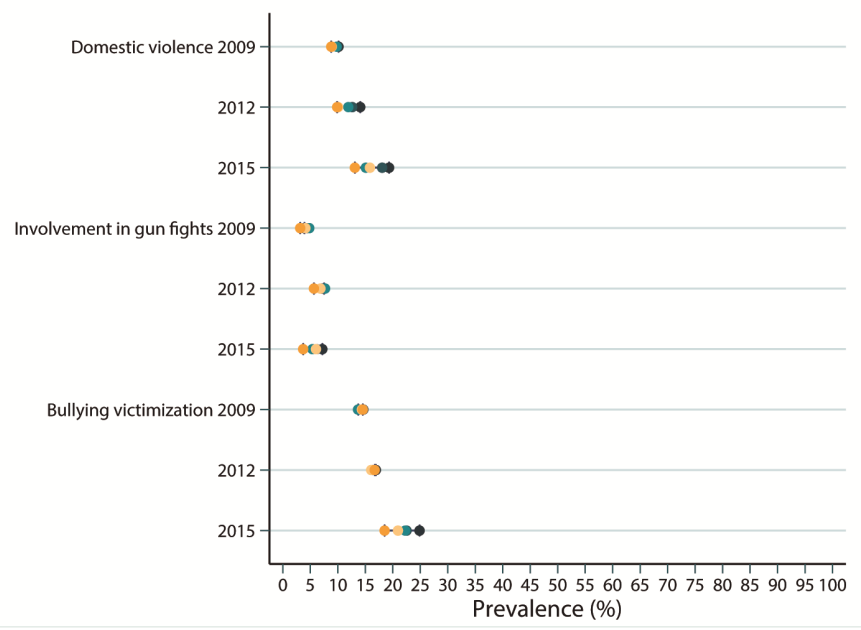

B. Engagement in risky activities

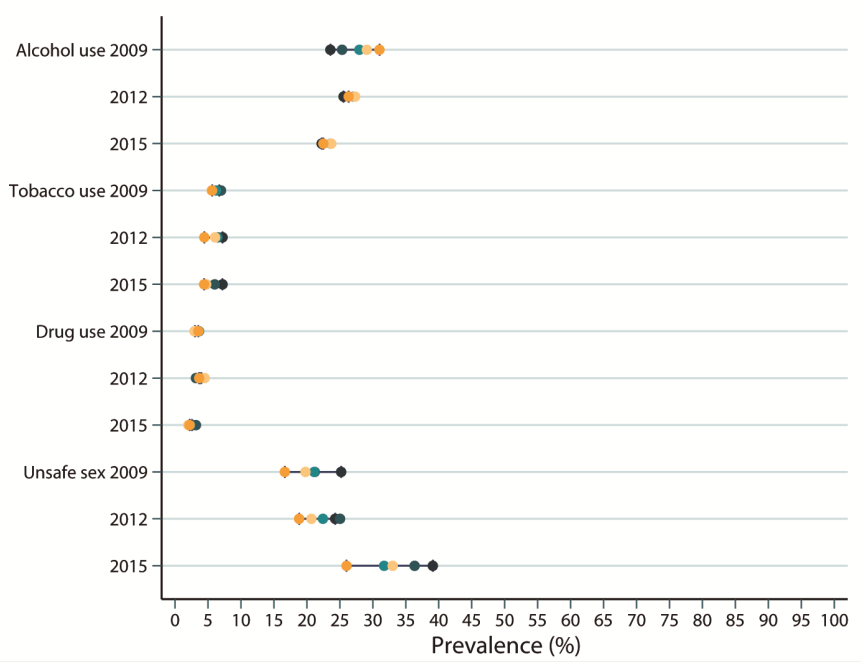

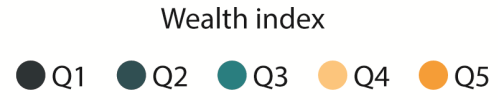

Figure 1 Time trends in health-related behaviours by wealthy quintile among adolescents.

In these countries, the reduction in alcohol use and soft drink consumption among those privileged is not necessarily followed by a reduction among those more socially deprived. ${ }^{5}$ Although this trend is measured as a reduction in inequality, it is not desirable.

The main strength of this study is to explore a wide spectrum of health indicators, which provides information on prevalence and trends in key risk factors for adolescent health. Another positive aspect is the large representative urban samples from Brazilian adolescents attending public and private schools. In Brazil, the school coverage in this age is very high $(88 \%-97 \%),{ }^{37}$ which reduces significantly the risk of selection bias. Despite this, it is plausible to assume that students at higher risk of harmful health behaviours have higher truancy and dropout rates. Therefore, this could have masked the true extent of the inequalities. We also report a range of simple and complex measures of inequalities to allow clear interpretation of trends as well as presenting rigorous hypothesis tests which make use of all data. Concordance between the absolute and relative measures of inequality adds strength to our conclusions.

Some limitations should be acknowledged. The engagement in health-related behaviours was self-reported by adolescents, and therefore, misclassification may have occurred towards social desirable behaviours. Misclassification likely affected the prevalence of health indicators similarly over three surveys. Although use of self-reported outcomes is a limitation, it is widely recognised as an acceptable and often the only feasible approach for monitoring adolescent health behaviours. ${ }^{38}$ Moreover, there is evidence of validity of the dietary indicators used in the PeNSE survey, ${ }^{17}$ and a US survey on which the PeNSE survey was based demonstrated good test-retest reliability and consistency across different modes of questioning. ${ }^{39}$ 
Table 3 Complex measures of inequality in health-related behaviours among Brazilian adolescents (Pesquisa Nacional da Saude do Escolar surveys 2009, 2012 and 2015)

\begin{tabular}{|c|c|c|c|c|c|c|c|c|}
\hline $\begin{array}{l}\text { Quintiles of wealth index (1=poorest; } \\
5=\text { wealthiest) } \\
\text { Indicators }\end{array}$ & \multicolumn{4}{|c|}{ Slope index of inequality (SII) } & \multicolumn{4}{|c|}{ Concentration index of inequality (CIX) } \\
\hline Irregular fruit consumption & -13.68 & -9.01 & -8.88 & 0.015 & -2.82 & -2.31 & -2.26 & 0.267 \\
\hline Irregular vegetable consumption & -19.02 & -17.59 & -17.92 & 0.535 & -4.30 & -4.48 & -5.18 & 0.165 \\
\hline Irregular bean consumption & 9.95 & 11.25 & 7.33 & 0.434 & 6.48 & 3.47 & 2.22 & $<0.001$ \\
\hline Regular soft drink consumption & 16.55 & 10.49 & 3.89 & $<0.001$ & 6.94 & 5.19 & 2.90 & $<0.001$ \\
\hline Alcohol use (once in the last month) & 9.69 & 0.68 & 0.06 & 0.000 & 4.79 & 1.71 & 1.19 & 0.004 \\
\hline Tobacco use (once in the last month) & -1.68 & -2.80 & -3.15 & 0.125 & -5.68 & -6.32 & -8.69 & 0.290 \\
\hline Drug use (once in the last month) & 0.34 & 0.46 & -0.98 & 0.048 & -0.08 & 4.47 & -4.61 & 0.428 \\
\hline Unsafe sex (in the last sexual intercourse) & -9.67 & -6.88 & -13.28 & 0.498 & -6.52 & -5.44 & -6.56 & 0.914 \\
\hline Domestic violence (once in the last month) & -1.84 & -5.24 & -6.92 & $<0.001$ & -2.72 & -7.02 & -6.57 & 0.014 \\
\hline
\end{tabular}

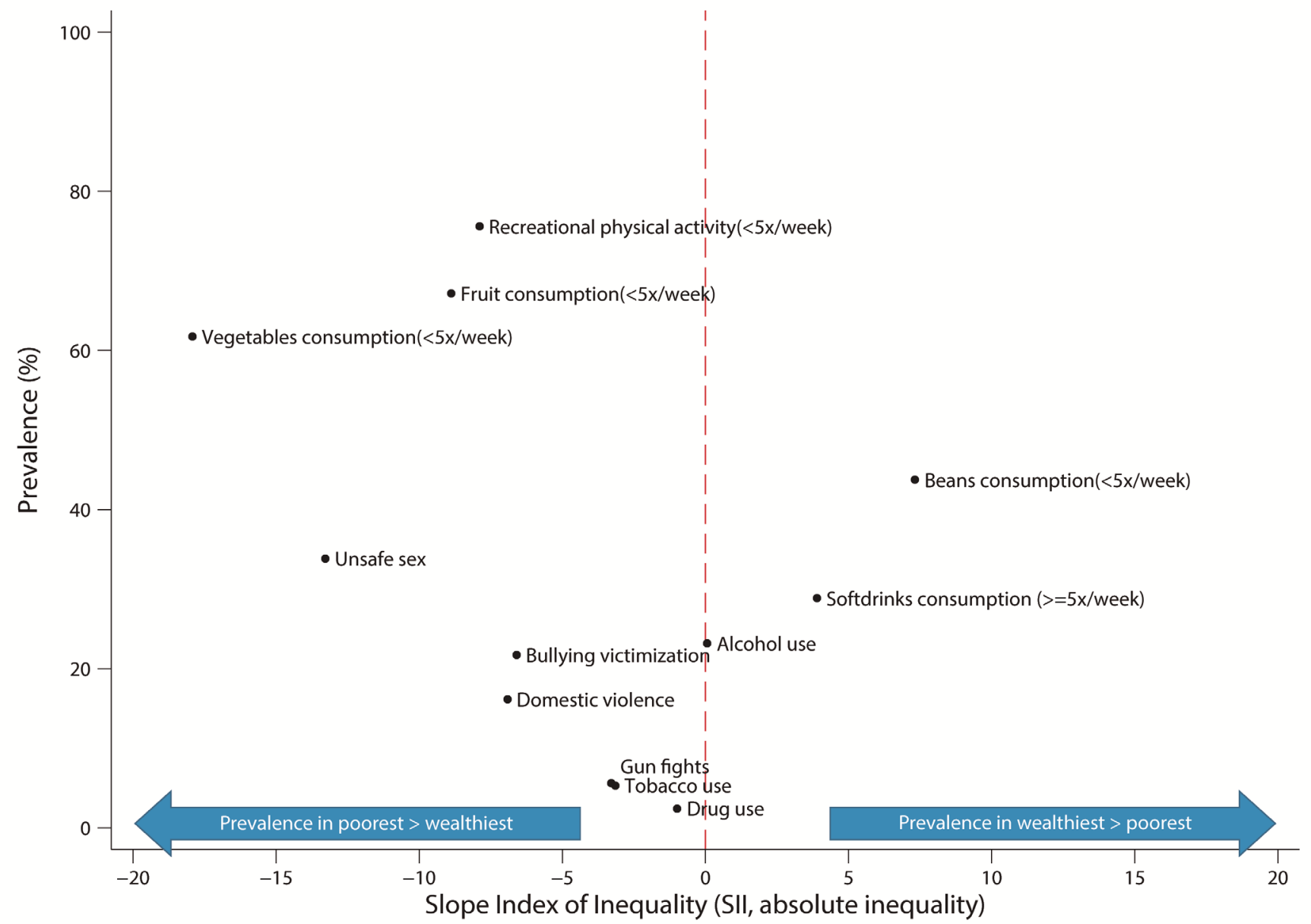

Figure 2 Prevalence of health-related behaviours among adolescents in 2015 and slope index of inequality (SII, absolute inequality). 
The surveys were available only for a period of 6 years, which may be too short to expect significant changes in inequalities. To continue monitoring trends in adolescent health inequality for longer periods is desirable. Also, the data analysed are representative of Brazilian state capitals, not the whole country. State capitals are highly urbanised cities and more developed than other cities; therefore, these results may not be generalisable to small cities and rural areas. However, state capitals are the most populous and unequal areas of Brazil, ${ }^{40}$ making them important settings for studying inequality trends, and meaning they can act as sentinels to the country as a whole.

Brazil is facing a huge economic recession since 2015, which deepened in 2016. Unemployment and inflation have increased and people's purchasing power has been reduced, with the poor especially affected. Therefore, it will be vital to continue monitoring the trends observed in this study and take action to prevent exacerbation of existing inequalities.

Policy makers and researchers should be alert to the fact that possible reductions in health risky behaviours may be unbalanced between social groups and even be increasing in disadvantaged social groups while decreasing on average. ${ }^{22}$ In this study, we found that the gap between poor adolescents and wealthy adolescents is reducing for lifestyle behaviours such as fruit consumption, while it is increasing for violent behaviours. For alcohol, irregular bean consumption and regular soft drink consumption, we found that the gap between social groups is narrowing, although represented by a reduction in these risk behaviours among the rich and an increase among poor adolescents.

\section{Author affiliations \\ ${ }^{1}$ Curso de Nutrição, Faculdade de Medicina, Universidade Federal de Uberlandia, Uberlandia, Brazil \\ ${ }^{2}$ Departamento de Medicina Preventiva, Faculdade de Medicina, Universidade de Sao Paulo, São Paulo, Brazil \\ ${ }^{3}$ Department of Non-Communicable Disease Epidemiology, London School of Hygiene and Tropical Medicine Faculty of Epidemiology and Population Health, London, UK \\ ${ }^{4}$ Postgraduate Programme in Epidemiology, Federal University of Pelotas (UFPel), Pelotas, Brazil}

Contributors CMA, LFMdR, RBL and AJDB conceptualised the study and were involved in the analysis and interpretation of the results. CZR was involved in data preparation, and designed and prepared the tables. SK and PACM were involved in the interpretation and discussion of results. The initial draft of the paper was prepared by CMA following extensive discussions and inputs from the other coauthors. All authors have reviewed, revised the manuscript and approved the final version.

Funding The present research received financial support from Brazilian National Council of Scientific and Technological Development (CNPq), 404905/2016-1, awarded to Catarina Machado Azeredo. Sao Paulo Research Foundation (FAPESP), grant \#2016/21390-0 and \#2014/25614-4 due to Leandro Fórnias Machado de Rezende.

Disclaimer The funders had no role in study design, data collection and analysis, decision to publish, or preparation of the manuscript.

Competing interests None declared.

Patient consent for publication Not required.

Provenance and peer review Not commissioned; externally peer reviewed.
Data sharing statement The dataset of 2009, 2012 and 2015 PeNSE are publicly available at: https://www.ibge.gov.br/estatisticas-novoportal/sociais/educacao/ 9134-pesquisa-nacional-de-saude-do-escolar.html?=\&t=microdados.

Open access This is an open access article distributed in accordance with the Creative Commons Attribution Non Commercial (CC BY-NC 4.0) license, which permits others to distribute, remix, adapt, build upon this work non-commercially, and license their derivative works on different terms, provided the original work is properly cited, appropriate credit is given, any changes made indicated, and the use is non-commercial. See: http://creativecommons.org/licenses/by-nc/4.0/.

\section{REFERENCES}

1. Sawyer SM, Afifi RA, Bearinger LH, et al. Adolescence: a foundation for future health. Lancet 2012;379:1630-40.

2. Patton GC, Sawyer SM, Santelli JS, et al. Our future: a Lancet commission on adolescent health and wellbeing. Lancet 2016;387:2423-78.

3. Viner RM, Ozer EM, Denny S, et al. Adolescence and the social determinants of health. Lancet 2012;379:1641-52.

4. Piketty T, Saez E. Inequality in the long run. Science 2014;344:838-43.

5. Elgar FJ, Pförtner TK, Moor I, et al. Socioeconomic inequalities in adolescent health 2002-2010: a time-series analysis of 34 countries participating in the health behaviour in school-aged children study. Lancet 2015;385:2088-95.

6. Solt F. The Standardized World Income Inequality Database*. Soc Sci Q 2016;97:1267-81.

7. Landmann-Szwarcwald C, Macinko J. A panorama of health inequalities in Brazil. Int J Equity Health 2016;15:174.

8. Martins AP, Monteiro CA. Impact of the Bolsa Família program on food availability of low-income Brazilian families: a quasi experimental study. BMC Public Health 2016;16:827.

9. Hone T, Rasella D, Barreto ML, et al. Association between expansion of primary healthcare and racial inequalities in mortality amenable to primary care in Brazil: a national longitudinal analysis. PLoS Med 2017;14:e1002306.

10. Rasella D, Harhay MO, Pamponet ML, et al. Impact of primary health care on mortality from heart and cerebrovascular diseases in Brazil: a nationwide analysis of longitudinal data. BMJ 2014;349:g4014.

11. IBGE. Pesquisa Nacional de Saúde do Escolar 2009. Ministério do Planejamento OeGIDdPCdPelS. 138. Rio de Janeiro: Instituto Brasileiro de Geografia e Estatística, 2009.

12. IBGE. Pesquisa Nacional de Saúde do Escolar 2012. Estatística IBdGe. 256. Rio de Janeiro: IBGE, 2013.

13. IBGE. Pesquisa Nacional de Saúde do Escolar: 2015. Ministério do Planejamento OeGIDdPCdPelS. 132. Rio de Janeiro: IBGE, 2016.

14. WHO. Global school-based student health surveillance (GSHS: Organization WHO, 2009.

15. Eaton DK, Kann L, Kinchen S, et al. Youth Risk Behavior Surveillance -United States- 2009. Services DOHAH, ed. United States. 148: Centers for Disease Control and Prevention (CDC), 2010.

16. Barros AJ, Victora CG. [A nationwide wealth score based on the 2000 Brazilian demographic census]. Rev Saude Publica 2005;39:523-9.

17. Tavares LF, Castro IR, Levy RB, et al. [Relative validity of dietary indicators from the Brazilian National School-Based Health Survey among adolescents in Rio de Janeiro, Brazil]. Cad Saude Publica 2014;30:1029-41.

18. Ha V, Sievenpiper JL, de Souza RJ, et al. Effect of dietary pulse intake on established therapeutic lipid targets for cardiovascular risk reduction: a systematic review and meta-analysis of randomized controlled trials. CMAJ 2014;186:E252-62.

19. Olweus D. Bullying at school: what we know and what we can do. Oxford, U.K.: Blackwell, 1993.

20. Mackenbach JP, Kunst AE. Measuring the magnitude of socioeconomic inequalities in health: an overview of available measures illustrated with two examples from Europe. Soc Sci Med 1997;44:757-71.

21. Barros AJ, Victora CG. Measuring coverage in $\mathrm{MNCH}$ : determining and interpreting inequalities in coverage of maternal, newborn, and child health interventions. PLoS Med 2013;10:e1001390.

22. WHO. Handbook on health inequality monitoring: with a special focus on low- and middle-income countries. 108. Geneva: World Health Organization, 2013.

23. Royston P, White I. Multiple Imputation by Chained Equations (MICE): implementation in Stata. J Stat Softw 2011;45:1-20.

24. Liu Y, Wang M, Tynjälä J, et al. Socioeconomic inequalities in alcohol use of adolescents: the differences between China and Finland. Int J Public Health 2013;58:177-85. 
25. Hargreaves DS, Djafari Marbini A, Viner RM. Inequality trends in health and future health risk among English children and young people, 1999-2009. Arch Dis Child 2013;98:850-5.

26. Rasmussen M, Pedersen TP, Johnsen NF, et al. Persistent social inequality in low intake of vegetables among adolescents, 20022014. Public Health Nutr 2018;21:1649-53.

27. Pickett W, Molcho M, Elgar FJ, et al. Trends and socioeconomic correlates of adolescent physical fighting in 30 countries. Pediatrics 2013;131:e18-26.

28. Beltrán-Sánchez H, Andrade FC. Time trends in adult chronic disease inequalities by education in Brazil: 1998-2013. Int J Equity Health 2016;15:139.

29. Mújica OJ, Vázquez E, Duarte EC, et al. Socioeconomic inequalities and mortality trends in BRICS, 1990-2010. Bull World Health Organ 2014:92:405-12.

30. Das J. Reassessing conditional cash transfer programs. World Bank Res Obs 2005;20:57-80.

31. Jaime PC, da Silva AC, Gentil PC, et al. Brazilian obesity prevention and control initiatives. Obes Rev 2013;14:88-95.

32. Viana LA, Costa MC, Paim JS, et al. Social inequalities and the rise in violent deaths in Salvador, Bahia State, Brazil: 2000-2006. Cad Saude Publica 2011;27:s298-308.

33. França EB, Passos VMA, Malta DC, et al. Cause-specific mortality for 249 causes in Brazil and states during 1990-2015: a systematic analysis for the global burden of disease study 2015. Popul Health Metr 2017;15:39.

34. Grittner U, Kuntsche S, Gmel G, et al. Alcohol consumption and social inequality at the individual and country levels--results from an international study. Eur J Public Health 2013;23:332-9.

35. Moodie R, Stuckler D, Monteiro $C$, et al. Profits and pandemics: prevention of harmful effects of tobacco, alcohol, and ultraprocessed food and drink industries. Lancet 2013;381:670-9.

36. Monteiro CA, Moubarac JC, Cannon G, et al. Ultra-processed products are becoming dominant in the global food system. Obes Rev 2013;14:21-8.

37. IBGE. Pesquisa Nacional por Amostra de Domicilios. Rio de Janeiro Brasil: IBGE, 2008.

38. Brener ND, Billy JO, Grady WR. Assessment of factors affecting the validity of self-reported health-risk behavior among adolescents: evidence from the scientific literature. J Adolesc Health 2003;33:436-57.

39. Brener ND, Kann L, Kinchen SA, et al. Methodology of the youth risk behavior surveillance system. MMWR Recomm Rep 2004;53:1-18.

40. IBGE. Síntese de indicadores sociais, uma análise das condições de vida. 147. Rio de Janeiro: IBGE, Coordenação de População e Indicadores Sociais, 2017. 